\title{
Monitoring shallow subsidence in cultivated peatlands
}

\author{
Sanneke van Asselen ${ }^{1}$, Gilles Erkens ${ }^{1,2}$, and Francis de Graaf ${ }^{3}$ \\ ${ }^{1}$ Deltares Research Institute, Daltonlaan 600, 3584 BK, Utrecht, the Netherlands \\ ${ }^{2}$ Utrecht University, Department of Physical Geography, Princetonlaan 8a, 3584 CB, Utrecht, the Netherlands \\ ${ }^{3}$ Waterschap (Waterboard) Drents Overijsselse Delta, Dokter van Deenweg 186, \\ 8025 BM, Zwolle, the Netherlands
}

Correspondence: Sanneke van Asselen (sanneke.vanasselen@deltares.nl)

Published: 22 April 2020

\begin{abstract}
Accurate monitoring of shallow subsidence in cultivated peatlands is a great challenge. Peat compaction by loading and peat oxidation by groundwater level lowering are two important processes contributing to shallow subsidence in cultivated peatlands, causing an overall increase in soil wetness over time and hence a lower soil-bearing capacity and agricultural production. Peat oxidation also causes emission of $\mathrm{CO}_{2}$ and other greenhouse gasses. Rigorous monitoring techniques are urgently needed to spatially and temporally map the amount and rate of subsidence and to monitor effects of measures to reduce subsidence and its negative impacts on livestock farming and agriculture. Monitoring shallow subsidence in peatlands is particularly challenging, because subsidence is a slow and spatially complex process, with average rates in the order of $\mathrm{mm} \mathrm{yr}^{-1}$ but with higher rates possibly occurring on shorter timescales. The desired monitoring system must be able to capture this temporal and spatial variability, and preferably the contribution of different processes to total subsidence. The system needs to be applicable (technically- and financially-speaking) at regional scales, without severely impacting daily farming activities. To help design and test a subsidence monitoring system for cultivated peatland areas, four methods to measure subsidence are applied and assessed in a cultivated peatland in Overijssel (NL), namely spirit levelling, extensometery, LiDAR, and InSAR. In this paper, we focus on the levelling and extensometery methods and measurements. Subsidence was measured since October 2018 at eight livestock farms once every three months by levelling. In the same period, extensometers have measured vertical movement of (sub)surface levels hourly at two livestock farms. In addition, phreatic groundwater levels are continuously monitored. Preliminary results show vertical movements (up and down) in the order of centimeters on the timescale of weeks. These movements seem to be related to groundwater level fluctuations, but also evapotranspiration is expected to contribute to additional subsidence during the summer period. Because long term net subsidence is a slow process, additional data collection is needed to assess the different methods and the temporal and spatial fluctuations in subsidence on longer timescales. This is vital information to design the optimal method for monitoring subsidence in cultivated peatlands on large spatial scales, and to help in selecting effective measures to reduce subsidence and greenhouse gas emission in peatlands.
\end{abstract}

\section{Introduction}

A large part of the coastal plain of The Netherlands contains as much as several meters of peat in the subsurface (Erkens et al., 2016). Like many other coastal plains worldwide, the Dutch coastal plain is subject to land subsidence from both anthropogenic and natural causes (Erkens et al., 2016; Van Asselen et al., 2018, and references therein). Human-induced subsidence is caused by loading of soft soils by fills and constructions, withdrawal of groundwater or hydrocarbons and artificial groundwater table lowering to increase the bearing capacity of the land. Subsidence increases flood risk, causes damage to buildings and infrastructure and an overall increase in soil wetness as the surface approaches the phreatic groundwater level. In agricultural areas this translates into a lower soil-bearing capacity affecting livestock farms, and 
damage to crops. In the Dutch coastal plain, subsidence has especially been caused by peat oxidation, peat compaction and peat mining in the Holocene sequence, starting about 1000 years ago (Erkens et al., 2016). Large scale peat mining continued until the late 19th century, after which subsidence has been mainly caused by peat compaction and oxidation. Peat compaction is the mechanical process of densification of the soil. Peat oxidation refers to the biogeochemical degradation of organic material by micro-organisms and occurs especially when peat is exposed to oxygen. Peat oxidation also causes the emission of greenhouse gasses.

The amount and rate of shallow subsidence in organicrich coastal sequences is determined by (1) geotechnical and biogeochemical properties of organic and mineral facies, (2) structural loading and (3) groundwater level fluctuations. These three aspects generally vary considerably in both time and space. Consequently, the amount and rate of subsidence is spatially and temporally variable: it varies between polders and even within parcels. During recent years, there is a growing incentive to reduce both subsidence and greenhouse gas emissions in the cultivated peatlands. To develop effective measures to reduce subsidence and to be able to monitor results of implemented measures, a monitoring system is needed that captures the temporal and spatial variability, and preferably also discriminates between the contribution of different processes.

One measure proposed to reduce subsidence and emission of $\mathrm{CO}_{2}$ in peat areas is the application of submerged drainage systems (Pleijter and van den Akker, 2007). This drainage technique is designed to enhance infiltration of ditch water to the parcels to elevate groundwater levels in dry (summer) periods, but at the same time to enhance drainage from the parcels to the ditches in wet (winter) periods to prevent too wet soils. Shallower groundwater levels in dry periods should result in less subsidence and greenhouse gas emissions due to peat oxidation. In the cultivated peatland study area, in the north-eastern part of the Netherlands, mainly used as meadows for livestock farming, submerged drainage was installed in 2018 at eleven farm fields (Fig. 1). The western part of the study area contains a nature reserve with peatland. The subsurface of the study area generally consists of a Holocene peat layer (Nieuwkoop Formation; De Mulder et al., 2003) as much as about $3.5 \mathrm{~m}$ thick, on top of a thick (tens of meters) Pleistocene sand deposit (mainly Boxtel and Kreftenheye Formations; De Mulder et al., 2003). In the western part of the study area, the peat layer is covered by a few dm-thick clayey top layer (Fig. 1; Naaldwijk Formation; De Mulder et al., 2003). Apart from the nature reserve and the eastern rim with sand outcropping at the surface, it is a seepage-prone area.

To determine the effects of submerged drainage on land subsidence, a monitoring system needs to be developed that (1) measures subsidence at mm-scale accuracy, since aver-

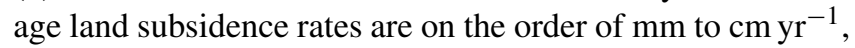
(2) captures the spatial and temporal variability of subsi-

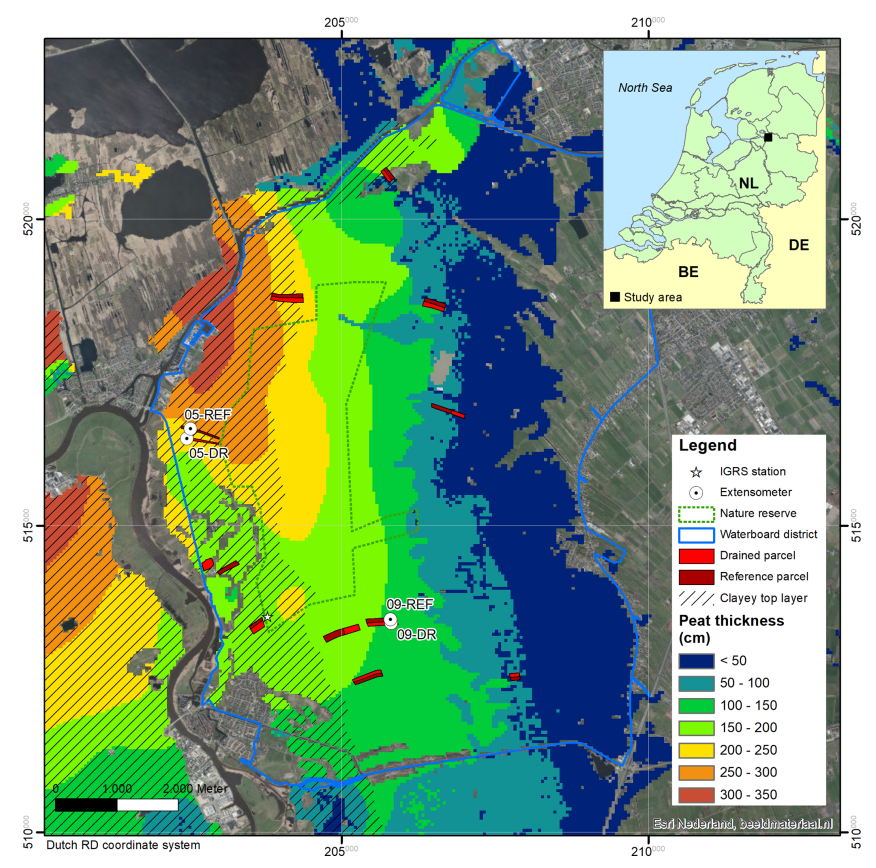

Figure 1. Study area with peat layer thickness (source: Waterboard Drents Overijselse Delta) and the location of measuring sites. In this paper results for sites 05 and 09 are presented (DR = drained, REF $=$ reference parcel).

dence at farm to regional scale, and (3) does not severely impact farming activities. To help design such a system, four different methods were or will be applied to monitor land subsidence in the parcel where submerged drainage was implemented and in a nearby reference parcel without submerged drainage. The methods used include conventional (spirit) levelling, extensometery, LiDAR (Light Detection And Ranging) and InSAR (Interferometric Synthetic Aperture Radar). Levelling is a well-tested and often-used technique for measuring surface elevation and has also been applied in a few cases in peat areas in the Netherlands (Pleijter and van den Akker, 2007). Extensometery is applied worldwide for measuring vertical movement of (sub)surface levels but have rarely been applied in peat areas. Both of these field-based techniques result in accurate (mm-scale) point measurements. The use of LiDAR and InSAR for measuring land subsidence in peat areas is promising but still experimental and the accuracy of the measurements needs testing. These two remote sensing techniques may ultimately result in timeseries of maps with spatial coverage, which is needed to monitor the temporal and spatial variability of land subsidence and the effects of applied mitigation measures.

In the study area, levelling and LiDAR have been applied once every three months at eight farms since October 2018. In the same period, four extensometers, distributed over two farms, have continuously measured vertical movement of different subsurface levels at $1 \mathrm{~h}$ intervals. InSAR analyses will start beginning of 2020. Because the LiDAR methodology 


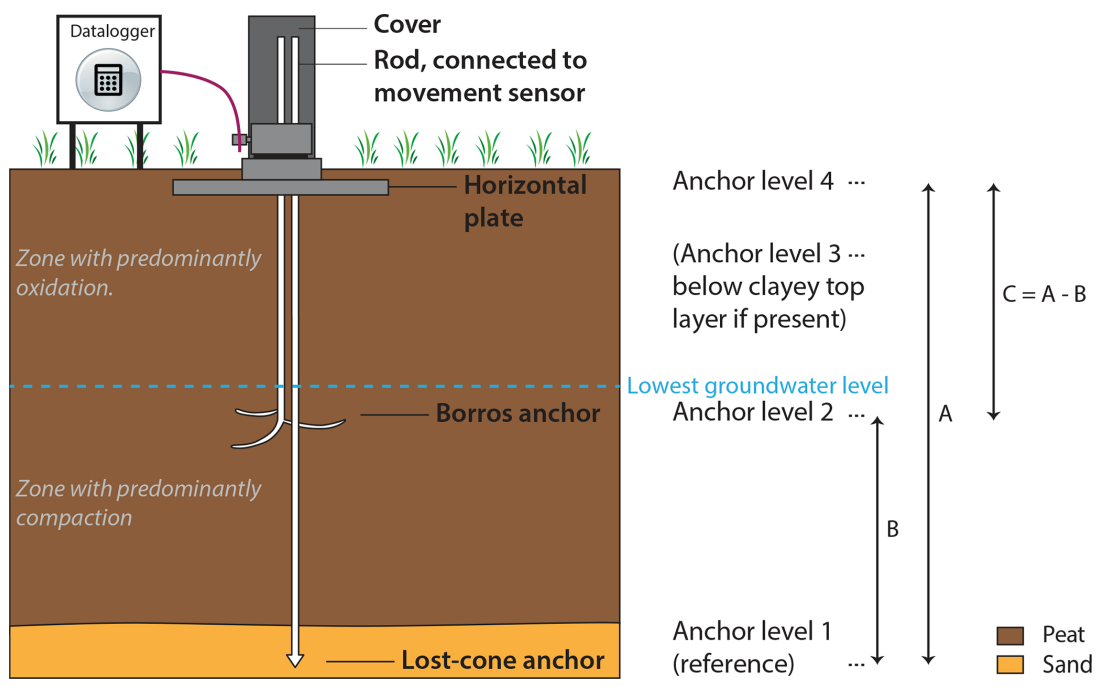

Figure 2. Schematic representation of extensometer set-up.

is still in the experimental phase, this paper focuses on the levelling and extensometery methodology. Both methods are described and assessed, and preliminary results and conclusions are presented.

\section{Methodology}

\subsection{Levelling}

The levelling methodology is based on Pleijter and van den Akker (2007) who applied this method in another Dutch cultivated peat area. Surface elevations are measured relative to a reference point, consisting of an iron rod that is founded in the semi-stable Pleistocene sand underlying the Holocene peat layer. In each parcel, reference and drained, such a reference point has been installed. The top of the rod is located about $10-15 \mathrm{~cm}$ below the surface and covered with a castiron road gully to protect it from disturbances by livestock and tractors, for example. The heights of the reference points are measured using an RTK-GNSS, for at least $15 \mathrm{~min}$, relative to local benchmarks (bolts fixed to concrete constructions founded on the Pleistocene sand; Fig. 1).

Surface elevations are measured relative to the reference point in the parcel four times a year using a Leica LS15 levelling instrument and rod. In each parcel, elevations are measured along four section lines in between and parallel to the drains at a $2 \mathrm{~m}$ interval as determined with a measuring tape. The start and end of the section lines are fixed coordinates determined each measuring campaign using a Topcon GRS1 RTK-GNSS. In each parcel, the groundwater level is monitored at one or two locations using standpipe piezometers and the ditch water level is monitored using gauges.

The spatial variability of surface elevations in peat meadows is usually higher than the long-term vertical movement of the surface due to peat compaction and oxidation. Surface irregularities are, for example, caused by cow tracks or grass tussocks. Therefore, a horizontal plate of $10 \times 10 \mathrm{~cm}$ is fixed to the bottom of the levelling rod to account for irregularities of the grass-covered surface. Also, one average elevation of the parcel is calculated for each measuring campaign. Finally, at local scale, the surface elevation is measured at ten points closely distributed around the reference point, which are also averaged.

\subsection{Extensometer}

Extensometers are used to measure compaction worldwide (e.g., Poland, 1984; Sneed and Brandt, 2015). However, they have rarely been applied in peat soils. Extensometers can be used to derive point measurements of vertical movement of different (sub)surface levels at mm-scale accuracy, and to determine the contribution of different layers, and in some cases processes, to total subsidence. In this study, we installed four extensometers that continuously measure the vertical movement of (sub)surface levels (Fig. 1). At two farms, one extensometer is installed in the drained parcel and one in the reference parcel, near the reference points. Different anchors are used at three or four different (sub)surface levels (Fig. 2). Anchor level 1 is a lost-cone anchor founded in the Pleistocene sand. This level is stable at the timescales considered (years), and hence, is used as reference level. Anchor level 2 is a Borros anchor positioned just below the average lowest groundwater level. At this level, vertical movement is measured that is mainly caused by processes acting in the saturated peat layer between level 1 and 2 (B in Fig. 2), presumably mainly compaction. In the overlying unsaturated zone, peat oxidation is likely to be the dominant process causing long-term subsidence. Anchor level 3 is a small rod driven into the subsurface just below a clayey top layer, if present (not visualized in Fig. 2). This level measures the contribu- 


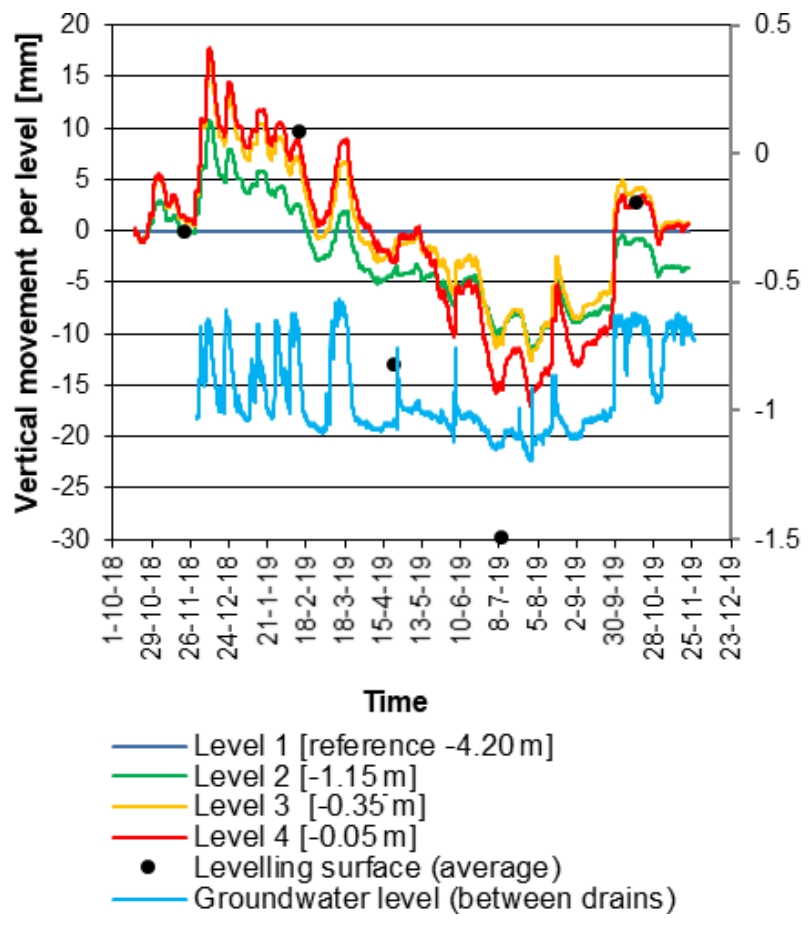

Figure 3. Preliminary results of extensometer, levelling and groundwater level measurements (parcel 05-DR; Fig. 1).

tion of the entire peat layer (total subsidence A in Fig. 2 minus contribution of clay layer, if present). Anchor level 4 is a perforated square stainless-steel plate of $0.4 \times 0.4 \mathrm{~m}$ positioned at about $5 \mathrm{~cm}$ below surface. This level measures vertical movements of the surface relative to level 1 (A in Fig. 2).

All sensors at the different levels are connected to a datalogger installed at the surface (Fig. 2). The vertical movement of the different levels is continuously and automatically measured at $1 \mathrm{~h}$ intervals.

\section{Preliminary results}

It will take years to collect a sufficiently long record on which firm conclusions can be drawn regarding the amount and rate of (long-term) land subsidence, its causes, and the effect of submerged drainage on land subsidence. Here we present preliminary results of the levelling and extensometer measurements for two farms in the study area (05 and 09 in Fig. 1). At location 05 the peat layer is about $3 \mathrm{~m}$ thick and overlain by a clay layer of about $40 \mathrm{~cm}$ thick. At location 09 the peat layer is about $1.25 \mathrm{~m}$ thick and is overlain by a $20 \mathrm{~cm}$ thick organic clay layer.

\subsection{Levelling results}

The average values for the reference and drained parcels of the two farms are presented in Table 1. Relative to the first measurement in November 2018 (T0), all parcels have on

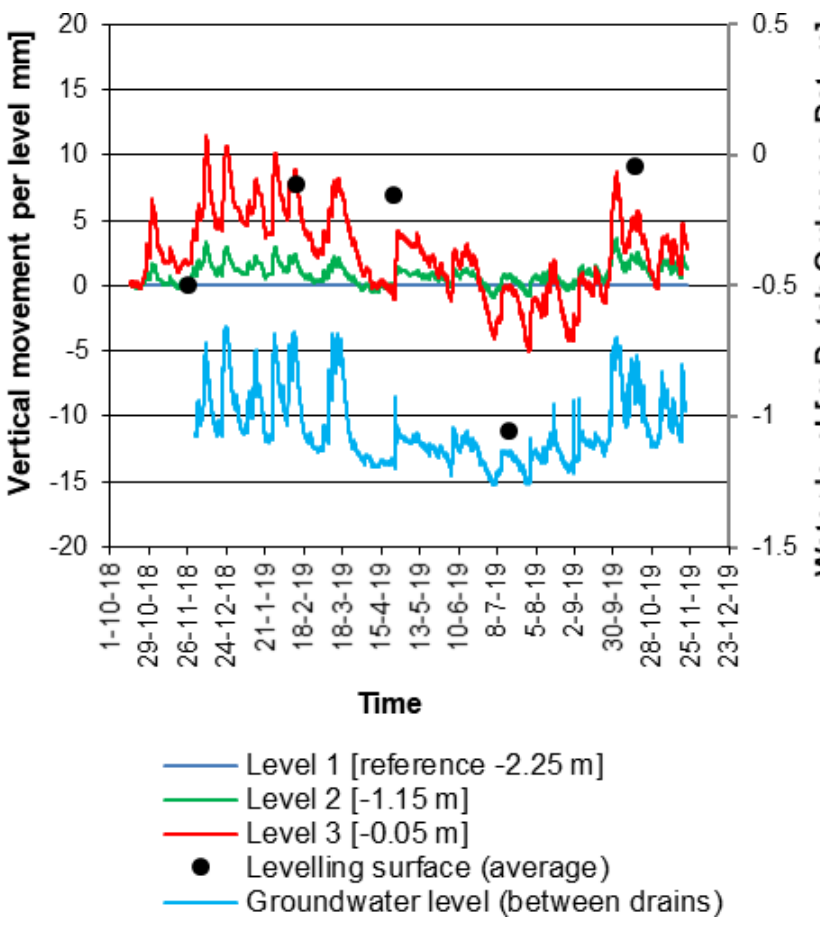

Figure 4. Preliminary results of extensometer, levelling and groundwater level measurements (parcel 09-DR; Fig. 1).

average risen about 8 to $10 \mathrm{~mm}$ in February 2019. Thereafter, compared to February 2019, all parcels show a subsiding trend during spring and summer. The greatest total vertical movement at a specific parcel measured in the period November 2018 to July 2019 is about $40 \mathrm{~mm}(+10$ to $-30 \mathrm{~mm}$ ), measured at 05-DR (Table 1).

\subsection{Extensometer results}

Extensometer results of locations 05-DR and 09-DR are presented in Figs. 3 and 4. These figures also include the averaged levelling values for these parcels. The results of the reference parcels are not presented here, since this paper focuses on methodologies and not on effects of submerged drainage, which yet cannot be determined. But, trends observed in reference parcels are seemingly similar to those observed in drained parcels. After installation of the extensometers in October 2018, a general rise of all (anchor) levels is observed at both locations, starting in December 2018. At 05-DR, anchor level 4, positioned just below the surface, has risen about $18 \mathrm{~mm}$. At 09-DR the surface level (3) has risen about $12 \mathrm{~mm}$. In the following months, a general subsiding trend is observed at both locations with week-scale fluctuations that relate to phreatic groundwater level fluctuations. However, the response of the surface movement to groundwater level fluctuations seems non-linear. Whereas, quickly after a substantial rise in groundwater level, all anchor levels rise, a lowering of the groundwater table results in a de- 
Table 1. Average vertical movement relative to T0 (November 2018; $n=114$ ). Standard deviation in (italic). Total vertical movement for a specific parcel $=$ max rise - max subsidence.

\begin{tabular}{lrrrrr}
\hline Parcel & $\begin{array}{r}\text { Feb 2019 } \\
(\mathrm{mm})\end{array}$ & $\begin{array}{r}\text { Apr 2019 } \\
(\mathrm{mm})\end{array}$ & $\begin{array}{r}\text { Jul 2019 } \\
(\mathrm{mm})\end{array}$ & $\begin{array}{r}\text { Oct 2019 } \\
(\mathrm{mm})\end{array}$ & $\begin{array}{r}\text { Total vertical } \\
\text { movement }(\mathrm{mm})\end{array}$ \\
\hline 05-DR & $9.7(12.9)$ & $-13.0(23.7)$ & $-29.9(19.2)$ & $2.7(29.0)$ & 39.6 \\
05-REF & $8.2(12.5)$ & $-20.1(13.4)$ & $-25.9(11.8)$ & $27.8(32.7)$ & 34.1 \\
09-DR & $7.8(6.1)$ & $7.0(8.8)$ & $-9.4(7.1)$ & $9.2(29.9)$ & 17.2 \\
09-REF & $9.4(8.0)$ & $4.4(10.8)$ & $-10.4(9.8)$ & $10.1(33.4)$ & 19.8 \\
\hline
\end{tabular}

layed response of the subsidence (e.g. in March 2019; Fig. 3). While the groundwater table has quickly returned to the pregroundwater table rise event level, the anchor levels continue to subside at slower pace. We also observe that average subsidence during spring and summer of the different levels occurs at higher rate than the lowering of groundwater level (no $1: 1$ relation). One explanation is that this may be related to increased microbiological activity, and hence subsidence by peat oxidation, during (warmer) spring and summer periods. Furthermore, assumingly, variable evapotranspiration rates causing soil shrink and swell also contribute to seasonal vertical ground movements. We also observe that the saturated peat significantly contributes to total vertical movements, especially at 05-DR, where the peat layer is thicker (level 2, Fig. 3). In July 2019, anchor level 4 at 05-DR has subsided to $-17 \mathrm{~mm}$ (Fig. 3). At 09-DR, the surface level (3) has subsided to $-5 \mathrm{~mm}$ in July 2019 (Fig. 4). Hence, the surface has vertically moved about $35 \mathrm{~mm}$ in about nine months' time at 05-DR and about $17 \mathrm{~mm}$ at 09-DR.

\section{Summary and concluding remarks}

A unique land subsidence monitoring site in a cultivated peat area in the Netherlands is presented. Two field-based techniques were used to monitor land subsidence at mm-scale at point locations quarterly (levelling) or continuously (extensometer). The extensometer results can be used to determine the contribution of different subsurface levels, i.e. processes. The accurate data derived from the field-based techniques can be used to assess the quality and optimize the more experimental air- and spaceborne techniques LiDAR and InSAR for use in rural areas. These techniques have high potential because they deliver time-series of spatial maps, allowing to determine spatial and temporal variations of land subsidence and assess effects of land management measures and other environmental conditions on these variations.

In this paper, the results of one-year measuring using levelling and extensometery are presented. Extensometers very convincingly show seasonal and weekly vertical movements of different subsurface levels, i.e. processes. Both methods have measured similar temporal trends. At the coeval measuring moments, the levelling results show a larger total vertical movement than extensometer measurements (Table 1;
Figs. 3 and 4). Specifically, for the October/November (2018 and 2019) and February measurements, the averaged levelling values plot at or close to the extensometer surface level line (Figs. 3 and 4). However, a larger deviation of up to $14 \mathrm{~mm}$ is observed during April and July at site 05 . One of the explanations may be that cow tracks and grass tussocks affect the levelling measurements in summer time. This needs close investigation in the future.

Preliminary results demonstrate $\mathrm{cm}$-scale elevation changes at weeks and months scale. This proves that a long (multiple years) monitoring period is needed to be able to filter out a land subsidence (or uplift) trend.

Data availability. No data sets were used in this article.

Author contributions. SvA coordinated all field measurements, analysed the resulting data and wrote this paper. GE supported at all these steps. FdG represents the Waterboard Drents Overijsselse Delta, who partly (besides Deltares) financed this research.

Competing interests. The authors declare that they have no conflict of interest. Gilles Erkens is member of the editorial board of this special issue but has not reviewed this paper, nor has he influenced the publication decision process.

Special issue statement. This article is part of the special issue "TISOLS: the Tenth International Symposium On Land Subsidence - living with subsidence". It is a result of the Tenth International Symposium on Land Subsidence, Delft, the Netherlands, 17-21 May 2021.

Acknowledgements. The authors thank the reviewer for constructive comments, which substantially improved this article.

Financial support. This research has been supported by Deltares Research Institute and Waterboard Drents Overijsselse Delta. 


\section{References}

De Mulder, E. F. J., Geluk, M. C., Ritsema, I., Westerhoff, W. E., and Wong, T. E.: De Ondergrond van Nederland, Geologie van Nederland, deel 7, Nederlands Instituut voor Toegepaste Geowetenschappen TNO, Utrecht, 379 pp., 2003 (in Dutch).

Erkens, G., van der Meulen, M. J., and Middelkoop, H.: Double trouble: subsidence and $\mathrm{CO}_{2}$ respiration due to 1,000 years of Dutch coastal peatlands cultivation, Hydrogeol. J., 24, 551-568, 2016.

Pleijter, M. and van den Akker, J. J. H.: Onderwaterdrains in het veenweidegebied: toelichting op de methode en meetinrichting, Wageningen Environmental Research report nr 1586, 2007 (in Dutch).
Poland, J. F.: Guidebook to Studies of Land Subsidence Due to Ground-water Withdrawal, UNESCO report, ISBN 92-3102213-X, 1984.

Sneed, M. and Brandt, J. T.: Land subsidence in the San Joaquin Valley, California, USA, 2007-2014, Proc. IAHS, 372, 23-27, 2015.

Van Asselen, S., Erkens, G., Stouthamer, E., Woolderink, H. A. G, Geeraert, R. E. E., and Hefting, M. M.: The relative contribution of peat compaction and oxidation to subsidence in built-up areas in the Rhine-Meuse delta, The Netherlands, Sci. Total Environ., 636, 177-191, 2018. 